\title{
Recent Advances in the Management of Cluster Headache
}

\author{
María Dolores Villar-Martínez, $M D^{1,2} \odot$ \\ Francesca Puledda, $M D^{1,2}$ \\ Peter J. Goadsby, MD, PhD, DSc ${ }^{1,2, *}$
}

\author{
Address \\ ${ }^{1}$ Department of Basic and Clinical Neuroscience, Institute of Psychology, Psychi- \\ atry and Neuroscience, King's College London, London, UK \\ ${ }^{*}{ }^{, 2}$ NIHR-Wellcome Trust King's Clinical Research Facility, SLaM Biomedical Re- \\ search Centre, King's College Hospital, Wellcome Foundation Building, London, \\ SE5 9PJ, UK \\ Email: peter.goadsby@kcl.ac.uk
}

Published online: 23 November 2020

(C) The Author(s) 2020

This article is part of the Topical Collection on Headache

Keywords Cluster headache - Calcitonin gene-related peptide · Neuromodulation • Vagal nerve stimulation • Sphenopalatine ganglion stimulation

\begin{abstract}
Purpose of review Among the spectrum of pain conditions, cluster headache represents one of the most severe. Targeted therapies for cluster headache are evolving thus improving the available therapeutic armamentarium. A better understanding of the currently available therapies, as well as new and emerging options, may aide physicians to manage affected sufferers better by evolving treatment guidance. Recent findings While classic firstline medications are useful in some patients with cluster headache, they are often accompanied by significant side effects that limit their use. Recently, novel treatments with better tolerability and decreased medication interactions have proven to be effective. A remarkable example of this is the blockage of the calcitonin gene-related peptide pathway with monoclonal antibodies, which may be a key element in the future treatment of cluster headache. The sphenopalatine ganglion and vagus nerve perform a critical role in the regulation of pain and the trigeminal autonomic reflex. Neuromodulation therapies targeting these structures have shown excellent tolerability and few significant adverse events, constituting a promising form of treatment. Finally, several potential therapeutic targets are examined in this review, such as small molecule CGRP receptor antagonists, known as gepants, and serotonin receptor 5- $\mathrm{HT}_{1 \mathrm{~F}}$ receptor agonists: ditans. Summary In summary, a deepening of the understanding of cluster headache mechanisms in recent years has driven the evolution of sophisticated therapeutic approaches that could allow a new era in the treatment of this difficult condition.
\end{abstract}




\section{Introduction}

Cluster headache $(\mathrm{CH})$ is a relatively rare primary headache disorder. It is the most common of the trigeminal autonomic cephalalgias (TACs) [1], with a population prevalence of approximately $0.1 \%[2,3]$. It is characterized by attacks of unilateral head pain that escalates rapidly [4], generally located in the orbital and supraorbital region, associated with ipsilateral cranial autonomic symptoms, such as conjunctival injection, lacrimation, rhinorrhoea and nasal congestion [5]. Some patients also report characteristically lateralized associated symptoms, such as photophobia or phonophobia [6, 7]. Affected patients typically report cluster headache as being the worst type of pain they have ever experienced $[8,9]$. The attacks of pain last between 15 and $180 \mathrm{~min}$, are usually followed by rapid offset of pain, in contrast with migraine and tend to have a circadian pattern with a nocturnal presentation, as well as a circannual seasonality with bouts lasting 6-12 weeks in its episodic form. In about $15 \%$ of cluster headache subjects [10, 11], the breaks between attack bouts last less than 3 months: classified as chronic cluster headache [5]. The frequency of attacks can go between one in $48 \mathrm{~h}$ and eight in $24 \mathrm{~h}$.
While the pathophysiology of cluster headache has not been entirely dissected, there are several proposed mechanisms described. These include a genetic predisposition [2], involvement of the trigeminovascular and cranial parasympathetic nervous systems and the role of the central nervous system and particularly of the hypothalamic region, which is thought to have a key role in the genesis of the attacks [12-14].

Given the severity of $\mathrm{CH}$, early diagnosis and adequate management of the acute attacks, as well as prevention during the bouts, and in the chronic form, are crucial. Fortunately, there are several options currently available to tackle this complex disorder. These include, as a first-line approach, primarily high-flow oxygen, intranasal zolmitriptan and sumatriptan, and subcutaneous sumatriptan for the acute treatment of attacks and verapamil for $\mathrm{CH}$ prevention [15].

This review will cover the well-established, first-line treatment options and then expand on newer targets and emerging therapies, which may represent a safer and better-tolerated option for $\mathrm{CH}$ management in the future.

\section{Classic acute attack treatments}

The aim of acute treatment in $\mathrm{CH}$ is to terminate the attack as quickly as possible, without headache recurrence and with a minimum of adverse events.

Oxygen is currently one of the most used acute medications for $\mathrm{CH}$, with nearly $80 \%$ of patients benefitting from its use [16]. Although its mechanism of action is not completely understood, possible components include an inhibition of responsive neurons on the trigeminocervical complex [17] and modification of neuropeptide release [18].

The effectiveness of high-flow oxygen in $\mathrm{CH}$ is remarkable; it is well tolerated with few adverse events; it is applicable repeatedly throughout the day and can also be combined with other treatments $[16,19,20]$. The major drawback for oxygen use is the portability of the cylinders [21]. Furthermore, it is not approved by the Food and Drug Administration (FDA), nor is it available or reimbursed in every country [22].

The possibility of a rebound headache after oxygen inhalation [23] can be mitigated by taking the treatment at the very beginning of the attack [24], by increasing the duration of inhalation or by selecting a different delivery system such as a demand valve system, which is preferred by some patients [25]. 


\section{Triptans (serotonin 5-HT 1 B/10 receptor agonists)}

Sumatriptan $6 \mathrm{mg}$ subcutaneous is an effective [26, 27] and safe option [28], which is both FDA and EMA approved and, unlike oxygen, compact and portable. Zolmitriptan $5 \mathrm{mg}[29,30]$ or sumatriptan $20 \mathrm{mg}$ [31] by nasal spray are reasonable and efficacious non-invasive options, especially for patients showing aichmophobia [29, 30]. Another needle-free presentation of zolmitriptan has been recently tested at $3.8 \mathrm{mg}$ as an intradermal microneedle patch in a randomized placebo-controlled study on migraine patients [32]. Although the endpoint aimed to discover significant differences in headache-free rates at $2 \mathrm{~h}$, the median time to maximum serum concentration $\left(t_{\max }\right)$ was less than $20 \mathrm{~min}$, making this medication a potential option for $\mathrm{CH}$ as well.

Triptans are contraindicated in patients with coronary and cerebrovascular diseases [33]. Other drawbacks include limits on daily usage [34] and a higher rate of side effects, compared to inhaled oxygen, viz. injection site reactions for sumatriptan, nausea, paraesthesia or chest tightness [26, 35].

\section{Classic treatments to prevent attacks}

The objective of preventive medication is to reduce the frequency of attacks, to decrease suffering and disability and to avoid issues linked to daily consumption of acute therapy.

Verapamil is a voltage-dependent calcium channel blocker. Its effect in cluster headache is not entirely elucidated and may be related to the prevention of CGRP release, by inhibition of presynaptic calcium influx [36]. At a daily dose of $240-960 \mathrm{mg}$, it represents the first-line preventive treatment for most patients with cluster headache $[15,37]$.

Recommendation for its use is based on small trials that showed efficacy in reducing the number of attacks in episodic [38] and chronic $\mathrm{CH}$ [39]. Verapamil has acceptable tolerability [39], although side effects such as constipation, ankle oedema and gingival hyperplasia are often reported at high doses [40]. The most critical side effects are certainly cardiac rhythm and atrioventricular abnormalities, through prolongation of the PR interval, which can develop in 19$38 \%$ of patients $[41,42]$. For this reason, electrocardiograms should be performed regularly during its use [42]. Verapamil is not approved by the FDA or EMA for CH [43].

Lithium carbonate exerts different modulatory actions, such as diminishing excitatory neurotransmission [44]. Lithium at the dose of $900 \mathrm{mg}$ demonstrated efficacy on chronic $\mathrm{CH}$, with a longer latency period in comparison with verapamil [39] and a larger number of adverse effects, including tremor or nausea [45]. Aside from these common side effects, treatment with lithium requires serum levels to be monitored and maintained within a range of 0.6$1.2 \mathrm{meq} / \mathrm{L}$ [46]. Furthermore, renal, liver and thyroid function needs to be checked regularly with long-term use [15]. 


\section{Topiramate}

Topiramate is a sulphamate derived from D-fructose. Its mechanism of action comprises at least three pathways: enhancing of GABA neurotransmission, decreasing glutamate levels and reducing of the activity of L-type calcium channels [47], among others [48]. Its use is recommended for cluster headache [15] based on case series [49-53], although not all series are positive [54].

Deterioration in cognitive function [55], weight loss and paraesthesia are frequently reported side effects of topiramate. The medication has also been associated with suicidal tendencies [56] and should thus be used with caution in at-risk subjects.

\section{Systemic corticosteroids}

The anti-inflammatory properties of corticosteroids could act in $\mathrm{CH}$ by modulating the hyperactivity of the trigeminal pathways and the hypothalamic dysfunction during a typical bout [57], although corticosteroid action is complex. There is some evidence for recommending either short-term decreasing doses of oral prednisone 60-100 mg for 5 days followed by a tapering of $10 \mathrm{mg} /$ day $[15,58,59]$ or intravenous methylprednisolone [60, 61]. Both of these treatments seem to be beneficial for short periods, yet their prolonged use is hindered by serious side effects, such as psychosis or osteonecrosis.

Greater occipital nerve (GON) blockade is a minimally invasive procedure consisting of an injection of corticosteroids mixed with local anaesthetic in the region of the most tender area of the suboccipital region. GON blocks have proven effective in $\mathrm{CH}$ in two randomized placebo-controlled trials $[62,63]$. Their effect could be attributed to a modulation of altered signalling at the trigeminocervical complex, where trigeminal and occipital afferents converge $[64,65]$. The long-term benefit and low rate of side effects, mostly mild and localized [66], make GON blocks a relevant option to be considered in the early treatment of cluster bouts [67]. There is limited evidence for the application of multiple cranial nerve injections [68] and a higher morbidity in comparison with a single injection.

Melatonin is a hormone that may exert an effect in cluster headache through its direct action on the suprachiasmatic nucleus of the hypothalamus [69]. A randomized placebo-controlled trial suggested that it is beneficial in $\mathrm{CH}$ at $10 \mathrm{mg}$ daily, especially in patients with an episodic pattern, and at the early stage of a bout [38]. It was not effective in chronic $\mathrm{CH}$, although this has been investigated with variable dose regimes [38, 70]. Melatonin is generally well tolerated [38], with mild drowsiness as the notable issue [71].

\section{Emerging treatments}

\section{The CGRP pathway}

Cranial serum CGRP rises in cluster headache during both spontaneous [18] and induced attacks [72] and is normalized with efficacious acute treatment, such as oxygen or sumatriptan [18]. Furthermore, CH attacks can be induced by 
CGRP infusion in patients with episodic cluster [73] and, with less consistency, in chronic $\mathrm{CH}$ patients using preventive treatment.

\section{Monoclonal antibodies against the CGRP pathway}

Antibodies targeting either the peptide or the canonical CGRP receptor are effective in the preventive treatment in migraine [74]. To date, only two of the available anti-CGRP pathway antibodies have been tested as a preventive treatment in cluster headache, namely galcanezumab and fremanezumab. Both are CGRP peptide monoclonal antibodies. The two remaining monoclonals, erenumab and eptinezumab, have so far only been studied for migraine prevention [75].

Galcanezumab is a subcutaneously administered humanized monoclonal antibody that neutralizes the CGRP peptide [76] that has recently been approved by the FDA for use in the prevention of episodic $\mathrm{CH}$. Galcanezumab $300 \mathrm{mg}$ was used in a multi-centre double-blind randomized placebocontrolled trial involving one-hundred and six patients, of whom forty-nine received the antibody. At the 3-week primary endpoint, a significant reduction in the frequency of attacks was achieved, with 3.5 less weekly attacks and 18\% more subjects in the active treatment group achieving a 50\% reduction compared to placebo. Furthermore, $21 \%$ of the subjects who discontinued the study were those randomized to the placebo group, in contrast to $8 \%$ of those who discontinued in the active group [77]. No severe side effects were reported, with injection site reactions as most commonly reported one, present in $8 \%$ of treated patients.

A second trial in the prevention of episodic cluster headache involved fremanezumab [78]. This study, however, was terminated early due to futility, as no significant efficacy difference was demonstrated between the treatment and placebo groups. An issue in the trial design was represented by the primary endpoint being set at 4 weeks, instead of earlier. Thus, the natural termination of the bouts' length could have played an important role in the benefit observed in the placebo group. It is noteworthy in this regard that both recent positive studies in episodic $\mathrm{CH}$, galcanezumab [77] and prednisone [59], set primary endpoints at 3 weeks and 1 week, respectively, in line with the natural history described in current trial guidance [79].

Interestingly, chronic cluster headache patients did not benefit either from galcanezumab [80] or from fremanezumab (NCT02797951).

Modulation of the peripheral nerve system, either of an invasive or non-invasive nature, is becoming an increasingly popular treatment option for the management of headache disorders. In the field of cluster headache, the most notable of these techniques with positive controlled trials are non-invasive vagus nerve stimulation (nVNS) and invasive sphenopalatine ganglion stimulation (SPG). Newer options such as percutaneous electrical nerve stimulation (PENS) and percutaneous pulsed radiofrequency are increasingly being studied as well.

\section{Non-invasive vagus nerve stimulation}

Transcutaneous stimulation of the vagus nerve has been tested in headache conditions through the use of the gammaCore ${ }^{\mathrm{TM}}$ (electroCore, LLC; Basking 
Ridge, NJ, USA), a device that transfers electrically stimulates the cervical branch of the vagus nerve in a non-invasive manner.

This approach was first studied systematically as an acute and preventive treatment of cluster headache in a clinical audit that showed encouraging results. In this initial study, almost $80 \%$ of the nineteen patients treated with gammaCore $^{\mathrm{TM}}$ responded to the treatment, either with reduced attack frequency or abortion of acute attacks [81]. Following the open-label study, two large randomized controlled trials tested the efficacy of nVNS as an acute treatment for $\mathrm{CH}$ in the USA-ACT1 study [82]—and Europe-ACT2 study [83]. The results from these studies showed that response rates, measured as either pain relief [82] or pain freedom [83] at 15 min from attack treatment, were significantly higher with nVNS than with sham. This was only found, however, in the episodic cluster headache cohort and not in chronic $\mathrm{CH}$ patients.

The PREVA study investigated the use of gammaCore ${ }^{\mathrm{TM}}$ as a preventive treatment in $\mathrm{CH}$ [84]. In this study, nVNS associated with standard of care (SoC) brought to a significantly greater reduction in the number of weekly cluster attacks compared to SoC alone, as well as to a significant reduction of the use of acute attack medication.

Based on the results of these studies, the gammaCore ${ }^{\mathrm{TM}}$ device is now CE marked in the European Union for acute and/or preventive treatment of cluster headache and has been FDA and NICE [85] approved for the treatment of both episodic and chronic $\mathrm{CH}$.

The mechanisms for nVNS efficacy in cluster headache are still mostly unknown, but hypotheses centre on possible effects on the trigeminovascular system through direct and indirect connections of the vagus nerve in the brainstem [86], dose-dependent modulation of trigeminocervical neurons [87] and specific connections between visceral vagal nuclei and areas of the pain matrix [88].

\section{Sphenopalatine ganglion stimulation}

The sphenopalatine ganglion is a pivotal structure in the pathophysiology of cluster headache and in particular of its typical cranial autonomic manifestations [89]. Modulation of the SPG was first attempted as acute treatment of $\mathrm{CH}$ in a proof of concept study involving five patients, using a removable electrode. In this study, the device resulted in a pain-free outcome in $61 \%$ of the eighteen treated attacks [90].

In the Pathway CH-1 study, the efficacy and safety of surgically implanted SPG stimulation were tested in twenty-eight European chronic refractory $\mathrm{CH}$ patients. Subjects were randomized to either active stimulation (lasting $15 \mathrm{~min}$ during the attack), sub-perception stimulation or sham [91]. Of the fivehundred and sixty-six treated attacks, treatment with active stimulation brought pain relief in $67 \%$ of cases, while sham and sub-threshold stimulation only in $7 \%$ of attacks.

The Pathway CH-2 study [92] was a randomized controlled trial involving ninety-three chronic $\mathrm{CH}$ patients based in the USA, treating their attacks with either active SPG stimulation or sham. Comparing SPG-stimulated and shamstimulated attacks, patients were more often pain free at $15 \mathrm{~min}$ with active treatment. The beneficial effects of SPG stimulation as an acute treatment for $\mathrm{CH}$ have been demonstrated in open-label registry study of thirty-three patients 
from the Pathway CH-1 study to persist for at least 2 years in two-thirds [93].

Implantation of the sphenopalatine ganglion is an invasive procedure that can cause adverse events, comprising swelling, pain and sensory disturbances in the site of implantation. In general, these side effects are well tolerated and resolve within a few months, very rarely have they required explantation of the device $[91,92]$.

In conclusion, SPG stimulation seems like a viable option for severely impaired $\mathrm{CH}$ patients, who have proved refractory to other non-invasive treatment.

\section{Forms of percutaneous stimulation}

A recent pilot study tested the efficacy of percutaneous electrical nerve stimulation of the occipital nerve in nine chronic $\mathrm{CH}$ patients. In total, six patients reported significant improvement, and in one case, reversion to episodic frequency of attacks was found [94]. The treatment was well tolerated with no significant adverse events.

Another retrospective study performed in twenty-one $\mathrm{CH}$ subjects refractory to other forms of treatment analysed the effects of percutaneous pulsed radiofrequency directed at the ganglion and/or nerve roots of the C1 and C2 levels [95]. The results of the study showed that a total of eleven patients reported some form of improvement in the 3 months following treatment and that no serious side effects were reported.

Further sham-controlled studies are required in the future to assess adequately the efficacy of these novel and promising forms of treatment.

\section{Other therapies}

\section{OnabotulinumtoxinA}

OnabotulinumtoxinA (OBTA) is a neurotoxin produced by clostridium botulinum that has been increasingly used in primary headaches. Its efficacy possibly involves a mechanism implicating the CGRP pathways, as revealed by a significant reduction of CGRP levels after 1 month of treatment in responsive patients with chronic migraine [96].

Its use as a preventive treatment in cluster headache has been investigated in three small open-label uncontrolled trials. Methods used in these trials varied considerably, including differences in doses, frequency of administration and injection site locations. Therefore, at the moment, the use of OnabotulinumtoxinA in cluster headache is not recommended [97]. In a recent study that followed the PREEMPT protocol, ten of seventeen refractory chronic $\mathrm{CH}$ patients treated with OBTA achieved a significant reduction in headache days [98], with mild side effects such as ptosis or a transient worsening in headaches.

Unilateral infiltration with OBTA 50 IU in the pericranial muscles [99] stopped the attacks of one out of nine patients with chronic $\mathrm{CH}$ and reduced the severity and intensity of two, with no benefit in the three episodic $\mathrm{CH}$ patients involved in the study, after 90 days. In this study, only one patient reported muscle weakness as a mild side effect. 
A more invasive technique tested a stereotactically guided injection of the sphenopalatine ganglion (SPG) with OBTA, using a percutaneous or transnasal approach and a heterogeneous number of repeated procedures [100, 101]. In the follow-up after the initial study [100], a reduction in the frequency and severity of the attacks, as well as an increase in attack-free days, was seen in five out of the seven treated patients. However, this analysis was per protocol and in the pilot study, one patient presented a severe preoperative posterior epistaxis [101].

\section{Future possibilities}

Cluster headache causes pain levels that rank among the most severe known to humans. For this reason, advancements in the understanding of its basic biology, as well as therapeutic developments, are necessary and encouraged.

Gepants are small molecule CGRP receptor antagonists that could be administered orally. Heretofore, these have only been studied in migraine [74]. Ubrogepant [102] and rimegepant [103] have proven efficacy against placebo in the acute treatment of migraine and are well tolerated. The relevance of these drugs lies in the possibility of being used multiple times without the drawbacks of medication overuse headache. Rimegepant (NCT03732638) and atogepant (NCT03855137) are currently being explored as migraine preventives. The latter produced a significant reduction in migraine days [104]. One attractive development would be the intranasal gepant, vazegepant (BHV3500-201), that has reported a positive study in the treatment of acute attacks of migraine [105].

Ditans are oral selective $5-\mathrm{HT}_{1 \mathrm{~F}}$ receptor agonists [106]. Lasmiditan inhibits nociceptive firing [107] and CGRP release [108] from the trigeminocervical complex, although it has until now solely been studied in migraine [109]. The lack of an effect in humans in vivo at $5 \mathrm{HT}_{1 \mathrm{~B} / 1 \mathrm{D}}$ receptors of these drugs might result in fewer side effects related to vasoconstriction [110] with respect to triptans, which would be useful in a condition in which the majority of patients are male and smokers.

Pituitary adenylate cyclase-activating polypeptide-38 or PACAP 38 is elevated in the active phase of episodic $\mathrm{CH}$ [111]. This peptide is related to the production of nitric oxide, a gaseous molecule that plays an important role in the vasodilation involved in the pathogenesis of cranial autonomic symptoms [112]. It is produced by the parasympathetic nerves [113], mostly during nociceptive processing [114]. Furthermore, plasma nitrite levels are elevated among $\mathrm{CH}$ patients [115]. The inhibition of nitric oxide synthase (NOS) with non-selective and selective NOS inhibitors is being studied in migraine [114]. A recently published paper describes the potential role of the inhibition of PAC1, a PACAP-38 highly selective receptor, and the stimulus-evoked activity in the trigeminocervical complex in animal models [116]. Nonetheless, blocking the PAC1 receptor with AMG 301 did not show differences in patients with episodic migraine (NCT03238781).

\section{Conclusions}

Cluster headache is a primary headache characterized by complex pathophysiological mechanisms that have only partially been elucidated. In recent years, a greater understanding of the basic biology of primary headaches has provided 
researchers with the tools to target specific pathways and design bespoke clinical studies, paving the way for novel treatments for clinical practice.

CGRP is a key element in the cluster headache pathway; new pharmacological therapies aimed at blocking it, such as monoclonal antibodies, have proven to be efficacious and well tolerated. Emerging treatments for migraine, such as gepants or ditans, could be viable options for cluster headache patients burdened by other comorbidities and vascular risk factors. Furthermore, the possibility of acute medication to be taken ad libitum without the risk of side effects or overuse is rather attractive. Neuromodulation techniques targeting crucial structures for the pathophysiology of $\mathrm{CH}$, such as the vagus nerve or the sphenopalatine ganglion, also represent well-tolerated preventive options.

Given the minimal amount of pharmacological interactions they present, a personalized combination of different novel therapies, targeting different elements involved in the nociceptive pathways, might well represent the future of treating cluster headache.

A broader knowledge of the mechanisms of chronification of cluster headache could help scientists and clinicians better understand the reason for refractory cases of the condition and optimize clinical benefit. Further studies are needed to understand the root of this relentless and extremely debilitating headache and to offer more adequate treatment strategies in the future.

\section{Funding}

This paper represents independent research funded by the National Institute for Health Research (NIHR) Biomedical Research Centre at South London and Maudsley NHS Foundation Trust and King's College London.

\section{Compliance with Ethical Standards}

\section{Conflict of Interest}

Maria Dolores Villar-Martinez has no disclosures. Francesca Puledda has received honoraria from Teva UK. Peter J Goadsby reports, over the last 36 months, grants and personal fees from Alder Biopharmaceuticals, Aeon Biopharma, Allergan, Biohaven Pharmaceuticals Inc., Clexio, Electrocore LLC, eNeura, Epalex, Impel Neuropharma, MundiPharma, Novartis, Pfizer, Santara Therapeutics, Teva Pharmaceuticals, Trigemina Inc., WL Gore, and personal fees from MedicoLegal work, Massachusetts Medical Society, Up-to-Date, Oxford University Press, and Wolters Kluwer; and a patent magnetic stimulation for headache assigned to eNeura without fee.

\section{Disclaimer}

The views expressed are those of the authors and not necessarily those of the NHS, the NIHR or the Department of Health and Social Care.

\section{Open Access}

This article is licensed under a Creative Commons Attribution 4.0 International License, which permits use, sharing, adaptation, distribution and reproduction in any medium or format, as long as you give appropriate credit to the original author(s) and the source, provide a link to the Creative Commons licence, and indicate if 
changes were made. The images or other third party material in this article are included in the article's Creative Commons licence, unless indicated otherwise in a credit line to the material. If material is not included in the article's Creative Commons licence and your intended use is not permitted by statutory regulation or exceeds the permitted use, you will need to obtain permission directly from the copyright holder. To view a copy of this licence, visit http://creativecommons.org/licenses/by/4.0/.

\section{References and Recommended Reading}

1. Goadsby PJ, Lipton RB. A review of paroxysmal hemicranias, SUNCT syndrome and other short-lasting headaches with autonomic feature, including new cases. Brain. 1997;120(Pt 1):193-209.

2. Russell MB. Epidemiology and genetics of cluster headache. Lancet Neurol. 2004;3(5):279-83.

3. Sjaastad O, Bakketeig LS. Cluster headache prevalence. Vaga study of headache epidemiology. Cephalalgia. 2003;23(7):528-33.

4. Wei DY, Khalil M, Goadsby PJ. Managing cluster headache. Pract Neurol. 2019;19(6):521-8.

5. Headache Classification Committee of the International Headache Society (IHS). The International Classification of Headache Disorders, 3rd edition. Cephalalgia. 2018;38(1):1-211.

6. Bahra A, May A, Goadsby PJ. Cluster headache: a prospective clinical study with diagnostic implications. Neurology. 2002;58(3):354-61.

7. Irimia P, Cittadini E, Paemeleire K, Cohen AS, Goadsby PJ. Unilateral photophobia or phonophobia in migraine compared with trigeminal autonomic cephalalgias. Cephalalgia. 2008;28(6):626-30.

8. Goadsby PJ. Trigeminal autonomic cephalalgias. Continuum (Minneap Minn). 2012;18(4):883-95.

9. Schor L. Cluster headache: investigating severity of pain, suicidality, personal burden, access to effective treatment, and demographics among a large international survey sample. Cephalalgia. 2017;37(1S):172208.

10. May A, Schwedt TJ, Magis D, Pozo-Rosich P, Evers S, Wang SJ. Cluster headache. Nat Rev Dis Primers. 2018;4:18006.

11. Hoffmann J, May A. Diagnosis, pathophysiology, and management of cluster headache. Lancet Neurol. 2018;17(1):75-83.

12. May A, Bahra A, Buchel C, Frackowiak RS, Goadsby PJ Hypothalamic activation in cluster headache attacks. Lancet. 1998;352(9124):275-8.

13. Goadsby PJ. Pathophysiology of cluster headache: a trigeminal autonomic cephalgia. Lancet Neurol. 2002;1(4):251-7.

14. May A. Cluster headache: pathogenesis, diagnosis, and management. Lancet. 2005;366:843-55.

15. May A, Leone M, Afra J, Linde M, Sandor PS, Evers S, et al. EFNS guidelines on the treatment of cluster headache and other trigeminal-autonomic cephalalgias. Eur J Neurol. 2006;13(10):1066-77.

16. Cohen AS, Burns B, Goadsby PJ. High-flow oxygen for treatment of cluster headache: a randomized trial. JAMA. 2009;302(22):2451-7.

17. Akerman S, Holland PR, Lasalandra MP, Goadsby PJ. Oxygen inhibits neuronal activation in the trigeminocervical complex after stimulation of trigeminal autonomic reflex, but not during direct dural activation of trigeminal afferents. Headache. 2009;49(8):1131-43.

18. Goadsby PJ, Edvinsson L. Human in vivo evidence for trigeminovascular activation in cluster headache. Neuropeptide changes and effects of acute attacks therapies. Brain. 1994;117(Pt 3):427-34.

19. Fogan L. Treatment of cluster headache. A doubleblind comparison of oxygen $\mathrm{v}$ air inhalation. Arch Neurol. 1985;42(4):362-3.

20. Schindler EAD, Wright DA, Weil MJ, Gottschalk $\mathrm{CH}$, Pittman BP, Sico JJ. Survey analysis of the use, effectiveness, and patient-reported tolerability of inhaled oxygen compared with injectable sumatriptan for the acute treatment of cluster headache. Headache. 2018;58(10):1568-78.

21. Lance JW, Goadsby PJ. Mechanism and management of headache, vol. xx. 7th ed. Philadelphia: Elsevier, Butterworth, Heinemann; 2005. p. 392.

22. Evers S, Rapoport A, Soc IH. The use of oxygen in cluster headache treatment worldwide - a survey of the International Headache Society (IHS). Cephalalgia. 2017;37(4):396-8.

23. Geerlings RP, Haane DY, Koehler PJ. Rebound following oxygen therapy in cluster headache. Cephalalgia. 2011;31(10):1145-9.

24. Igarashi H, Sakai F, Kanda T, Tazaki Y, Saitoh Y. The mechanism by which oxygen interrupts cluster headache. Cephalalgia. 1991;11:238-9.

25. Petersen AS, Barloese MC, Lund NL, Jensen RH. Oxygen therapy for cluster headache. A mask comparison trial. A single-blinded, placebo-controlled, crossover study. Cephalalgia. 2017;37(3):214-24.

26. The Sumatriptan Cluster Headache Study Group. Treatment of acute cluster headache with sumatriptan. N Engl J Med. 1991;325(5):322-6.

27. Ekbom K, Monstad I, Prusinski A, Cole JA, Pilgrim AJ, Noronha D. Subcutaneous sumatriptan in the acute 
treatment of cluster headache: a dose comparison study. The Sumatriptan Cluster Headache Study Group. Acta Neurol Scand. 1993;88(1):63-9.

28. Ekbom K, Krabbe A, Micieli G, Prusinski A, Cole JA, Pilgrim AJ, et al. [corrected to Micieli G]Cluster headache attacks treated for up to three months with subcutaneous sumatriptan (6 mg). Sumatriptan Cluster Headache Long-term Study Group. Cephalalgia. 1995;15(3):230-6.

29. Rapoport AM, Mathew NT, Silberstein SD, Dodick D, Tepper SJ, Sheftell FD, et al. Zolmitriptan nasal spray in the acute treatment of cluster headache: a double-blind study. Neurology. 2007;69(9):821-6.

30. Cittadini E, May A, Straube A, Evers S, Bussone G, Goadsby PJ. Effectiveness of intranasal zolmitriptan in acute cluster headache: a randomized, placebo-controlled, double-blind crossover study. Arch Neurol. 2006;63(11):1537-42.

31. van Vliet JA, Bahra A, Martin V, Ramadan N, Aurora SK, Mathew NT, et al. Intranasal sumatriptan in cluster headache: randomized placebo-controlled doubleblind study. Neurology. 2003;60(4):630-3.

32. Spierings EL, Brandes JL, Kudrow DB, Weintraub J, Schmidt PC, Kellerman DJ, et al. Randomized, doubleblind, placebo-controlled, parallel-group, multi-center study of the safety and efficacy of ADAM zolmitriptan for the acute treatment of migraine. Cephalalgia. 2018;38(2):215-24.

33. Dodick D, Lipton RB, Martin V, Papademetriou V, Rosamond W, MaassenVanDenBrink A, et al. Consensus statement: cardiovascular safety profile of triptans (5-HT agonists) in the acute treatment of migraine. Headache. 2004;44(5):414-25.

34. National Clinical Guideline Centre. Headaches in over 12s: diagnosis and management. In: National Institute for Health and Clinical Excellence, editor. 2012. http:// www.nice.org.uk/guidance/cg150. Accessed 16 Apr 2020.

35. Brown EG, Endersby CA, Smith RN, Talbot JC. The safety and tolerability of sumatriptan: an overview. Eur Neurol. 1991;31(5):339-44.

36. Akerman S, Williamson DJ, Goadsby PJ. Voltagedependent calcium channels are involved in neurogenic dural vasodilatation via a presynaptic transmitter release mechanism. Br J Pharmacol. 2003;140(3):558-66.

37. Robbins MS, Starling AJ, Pringsheim TM, Becker WJ, Schwedt TJ. Treatment of cluster headache: the American headache society evidence-based guidelines. Headache. 2016;56(7):1093-106.

38. Leone M, D'Amico D, Moschiano F, Fraschini F, Bussone G. Melatonin versus placebo in the prophylaxis of cluster headache: a double-blind pilot study with parallel groups. Cephalalgia. 1996;16(7):494-6.

39. Bussone G, Leone M, Peccarisi C, Micieli G, Granella F, Magri $M$, et al. Double blind comparison of lithium and verapamil in cluster headache prophylaxis. Headache. 1990;30(7):411-7.

40. Matharu MS, van Vliet JA, Ferrari MD, Goadsby PJ. Verapamil induced gingival enlargement in cluster headache. J Neurol Neurosurg Psychiatry. 2005;76(1):124-7.

41. Lanteri-Minet M, Silhol F, Piano V, Donnet A. Cardiac safety in cluster headache patients using the very high dose of verapamil ( $>/=720 \mathrm{mg} /$ day). J Headache Pain. 2011;12(2):173-6.

42. Cohen AS, Matharu MS, Goadsby PJ. Electrocardiographic abnormalities in patients with cluster headache on verapamil therapy. Neurology. 2007;69(7):668-75.

43. Petersen AS, Barloese MCJ, Snoer A, Soerensen AMS, Jensen RH. Verapamil and cluster headache: still a mystery. A narrative review of efficacy, mechanisms and perspectives. Headache. 2019;59(8):1198-211.

44. Costa A, Antonaci F, Ramusino MC, Nappi G. The neuropharmacology of cluster headache and other trigeminal autonomic cephalalgias. Curr Neuropharmacol. 2015;13(3):304-23.

45. Steiner TJ, Hering R, Couturier EG, Davies PT, Whitmarsh TE. Double-blind placebo-controlled trial of lithium in episodic cluster headache. Cephalalgia. 1997; 17(6):673-5.

46. Manzoni GC, Bono G, Lanfranchi M, Micieli G, Terzano MG, Nappi G. Lithium carbonate in cluster headache: assessment of its short- and long-term therapeutic efficacy. Cephalalgia. 1983;3(2):109-14.

47. Cutrer FM. Antiepileptic drugs: how they work in headache. Headache. 2001;41(Suppl 1):S3-10.

48. Rosenfeld WE. Topiramate: a review of preclinical, pharmacokinetic, and clinical data. Clin Ther. 1997;19(6):1294-308.

49. Forderreuther S, Mayer M, Straube A. Treatment of cluster headache with topiramate: effects and sideeffects in five patients. Cephalalgia. 2002;22(3):186-9.

50. Lainez MJ, Pascual J, Pascual AM, Santonja JM, Ponz A, Salvador A. Topiramate in the prophylactic treatment of cluster headache. Headache. 2003;43(7):784-9.

51. Mathew NT, Kailasam J, Meadors L. Prophylaxis of migraine, transformed migraine, and cluster headache with topiramate. Headache. 2002;42(8):796-803.

52. Rapoport AM, Bigal ME, Tepper SJ, Sheftell FD. Treatment of cluster headache with topiramate: effects and side-effects in five patients. Cephalalgia.

2003;23(1):69-70 author reply.

53. Wheeler SD, Carrazana EJ. Topiramate-treated cluster headache. Neurology. 1999;53(1):234-6.

54. Leone M, Dodick D, Rigamonti A, D'Amico D, Grazzi $\mathrm{L}$, Mea E, et al. Topiramate in cluster headache prophylaxis: an open trial. Cephalalgia. 2003;23(10):1001-2.

55. Ozturk B, Ovunc Ozon A, Karadas O. Evaluation of cognitive functions in migraineurs treated with topiramate. J Clin Neurosci. 2019;59:89-92.

56. Christman DS, Faubion MD. Suicide attempt following initiation of topiramate. Am J Psychiatry. 2007;164(4):682-3.

57. Neeb L, Anders L, Euskirchen P, Hoffmann J, Israel H, Reuter U. Corticosteroids alter CGRP and melatonin release in cluster headache episodes. Cephalalgia. 2015;35(4):317-26. 
58. Jammes JL. The treatment of cluster headaches with prednisone. Dis Nerv Syst. 1975;36(7):375-6.

59. Obermann M, Holle D. Prednisone in short-term prevention of episodic cluster headache. Neurology (Minneap). 2020;94(15 Suppl):S58.002.

60. Cianchetti C, Zuddas A, Marchei F. High dose intravenous methylprednisolone in cluster headache. J Neurol Neurosurg Psychiatry. 1998;64(3):418.

61. Mir P, Alberca R, Navarro A, Montes E, Martinez E, Franco E, et al. Prophylactic treatment of episodic cluster headache with intravenous bolus of methylprednisolone. Neurol Sci. 2003;24(5):318-21.

62. Ambrosini A, Vandenheede M, Rossi P, Aloj F, Sauli E, Pierelli F, et al. Suboccipital injection with a mixture of rapid- and long-acting steroids in cluster headache: a double-blind placebo-controlled study. Pain. 2005;118(1-2):92-6.

63. Leroux E, Valade D, Taifas I, Vicaut E, Chagnon M, Roos C, et al. Suboccipital steroid injections for transitional treatment of patients with more than two cluster headache attacks per day: a randomised, double-blind, placebo-controlled trial. Lancet Neurol.

2011;10(10):891-7.

64. Goadsby PJ, Holland PR. An update: pathophysiology of migraine. Neurol Clin. 2019;37(4):651-71.

65. Busch V, Jakob W, Juergens T, Schulte-Mattler W, Kaube H, May A. Functional connectivity between trigeminal and occipital nerves revealed by occipital nerve blockade and nociceptive blink reflexes. Cephalalgia. 2006;26(1):50-5.

66. Afridi SK, Shields KG, Bhola R, Goadsby PJ. Greater occipital nerve injection in primary headache syndromes-prolonged effects from a single injection. Pain. 2006;122(1-2):126-9.

67. Gonen M, Balgetir F, Aytac E, Tasci I, Demir CF, Mungen B. Suboccipital steroid injection alone as a preventive treatment for cluster headache. J Clin Neurosci. 2019;68:140-5.

68. Miller S, Lagrata S, Matharu M. Multiple cranial nerve blocks for the transitional treatment of chronic headaches. Cephalalgia. 2019;39(12):1488-99.

69. Gelfand AA, Goadsby PJ. The role of melatonin in the treatment of primary headache disorders. Headache. 2016;56(8):1257-66.

70. Pringsheim T, Magnoux E, Dobson CF, Hamel E, Aube M. Melatonin as adjunctive therapy in the prophylaxis of cluster headache: a pilot study. Headache.

2002;42(8):787-92.

71. Nordlund JJ, Lerner AB. The effects of oral melatonin on skin color and on the release of pituitary hormones. J Clin Endocrinol Metab. 1977;45(4):768-74.

72. Fanciullacci M, Alessandri M, Figini M, Geppetti $P$, Michelacci S. Increase in plasma calcitonin gene-related peptide from the extracerebral circulation during nitroglycerin-induced cluster headache attack. Pain. 1995;60(2):119-23.

73. Vollesen ALH, Snoer A, Beske RP, Guo S, Hoffmann J, Jensen $\mathrm{RH}$, et al. Effect of infusion of calcitonin generelated peptide on cluster headache attacks: a randomized clinical trial. JAMA Neurol. 2018;75(10):1187-97.

74. Goadsby PJ. Primary headache disorders: five new things. Neurol Clin Pract. 2019;9(3):233-40.

75. Chan C, Goadsby PJ. Recent advances in pharmacotherapy for episodic migraine. CNS Drugs. 2019;33(11):1053-71.

76. Benschop RJ, Collins EC, Darling RJ, Allan BW, Leung D, Conner EM, et al. Development of a novel antibody to calcitonin gene-related peptide for the treatment of osteoarthritis-related pain. Osteoarthr Cartil. 2014;22(4):578-85.

77. Goadsby PJ, Dodick DW, Leone M, Bardos JN, Oakes TM, Millen BA, et al. Trial of galcanezumab in prevention of episodic cluster headache. N Engl J Med. 2019;381(2):132-41.

78. Lipton RBDH, Barbanti P, Schiemann J, Barash S, Cohen JM, et al. Efficacy and safety of fremanezumab for the prevention of episodic cluster headache: results of a randomized, double-blind, placebo-controlled, phase 3 study. Cephalalgia. 2019;39(1S):358-9.

79. Lipton RB, Micieli G, Russell D, Solomon S, TfeltHansen P, Waldenlind E. Guidelines for controlled trials of drugs in cluster headache. Cephalalgia. 1995; 15(6):452-62.

80. Dodick DW, Goadsby PJ, Lucas C, Jensen R, Bardos JN, Martinez J, et al. Phase 3 randomized trial of galcanezumab in chronic cluster headache: doubleblind treatment. Cephalalgia. 2019;39:46-7.

81. Nesbitt AD, Marin JC, Tompkins E, Ruttledge $\mathrm{MH}$, Goadsby PJ. Initial use of a novel noninvasive vagus nerve stimulator for cluster headache treatment. Neurology. 2015;84(12):1249-53.

82. Silberstein SD, Mechtler LL, Kudrow DB, Calhoun AH, McClure C, Saper JR, et al. Non-invasive vagus nerve stimulation for the acute treatment of cluster headache: findings from the randomized, double-blind, shamcontrolled ACT1 study. Headache. 2016;56(8):131732.

83. Goadsby PJ, de Coo IF, Silver N, Tyagi A, Ahmed F, Gaul C, et al. Non-invasive vagus nerve stimulation for the acute treatment of episodic and chronic cluster headache: a randomized, double-blind, shamcontrolled ACT2 study. Cephalalgia. 2018;38(5):95969.

84. Gaul C, Diener HC, Silver N, Magis D, Reuter U, Andersson A, et al. Non-invasive vagus nerve stimulation for prevention and acute treatment of chronic cluster headache (PREVA): a randomised controlled study. Cephalalgia. 2016;36(6):534-46.

85. National Clinical Guideline Centre. gammaCore. In: National Institute for Health and Clinical Excellence, editor. 2019. http://www.nice.org.uk/guidance/mtg46. Accessed 16 Apr 2020.

86. Yuan H, Silberstein SD. Vagus nerve and vagus nerve stimulation, a comprehensive review: part I. Headache. 2016;56(1):71-8.

87. Akerman S, Simon B, Romero-Reyes M. Vagus nerve stimulation suppresses acute noxious activation of 
trigeminocervical neurons in animal models of primary headache. Neurobiol Dis. 2017;102:96-104.

88. Henssen D, Derks B, van Doorn M, Verhoogt N, Van Cappellen van Walsum AM, Staats $P$, et al. Vagus nerve stimulation for primary headache disorders: an anatomical review to explain a clinical phenomenon. Cephalalgia. 2019;39(9):1180-94.

89. May A, Goadsby PJ. The trigeminovascular system in humans: pathophysiologic implications for primary headache syndromes of the neural influences on the cerebral circulation. J Cereb Blood Flow Metab. 1999;19(2):115-27.

90. Ansarinia M, Rezai A, Tepper SJ, Steiner CP, Stump J, Stanton-Hicks $\mathrm{M}$, et al. Electrical stimulation of sphenopalatine ganglion for acute treatment of cluster headaches. Headache. 2010;50(7):1164-74.

91. Schoenen J, Jensen RH, Lanteri-Minet M, Lainez MJ, Gaul C, Goodman AM, et al. Stimulation of the sphenopalatine ganglion (SPG) for cluster headache treatment. Pathway $\mathrm{CH}-1$ : a randomized, shamcontrolled study. Cephalalgia. 2013;33(10):816-30.

92. Goadsby PJ, Sahai-Srivastava S, Kezirian EJ, Calhoun AH, Matthews DC, McAllister PJ, et al. Safety and efficacy of sphenopalatine ganglion stimulation for chronic cluster headache: a double-blind, randomised controlled trial. Lancet Neurol. 2019;18(12):1081-90.

93. Jurgens TP, Barloese M, May A, Lainez JM, Schoenen J, Gaul C, et al. Long-term effectiveness of sphenopalatine ganglion stimulation for cluster headache. Cephalalgia. 2017;37(5):423-34.

94. Weatherall MW, Nandi D. Percutaneous electrical nerve stimulation (PENS) therapy for refractory primary headache disorders: a pilot study. Br J Neurosurg. 2019;33(6):608-12.

95. Kelderman. Safety and efficacy of percutaneous pulsed radiofrequency treatment at the $\mathrm{C} 1-\mathrm{C} 2$ level in chronic cluster headache: a retrospective analysis of 21 cases. Acta Neurol Belg. 2019;119(4):601-5.

96. Cernuda-Morollon E, Ramon C, Martinez-Camblor P, Serrano-Pertierra E, Larrosa D, Pascual J. OnabotulinumtoxinA decreases interictal CGRP plasma levels in patients with chronic migraine. Pain. 2015;156(5):820-4.

97. Freund B, Kotchetkov IS, Rao A. The efficacy of botulinum toxin in cluster headache: a systematic review. J Oral Facial Pain Headache. 2020;34(2):129-34.

98. Lampl C, Rudolph M, Brautigam E. OnabotulinumtoxinA in the treatment of refractory chronic cluster headache. J Headache Pain. 2018;19(1):45.

99. Sostak P, Krause P, Forderreuther S, Reinisch V, Straube A. Botulinum toxin type-A therapy in cluster headache: an open study. J Headache Pain. 2007;8(4):236-41.

100. Aschehoug I, Bratbak DF, Tronvik EA. Long-term outcome of patients with intractable chronic cluster headache treated with injection of onabotulinum toxin a toward the sphenopalatine ganglion - an observational study. Headache. 2018;58(10):1519-29.
101. Bratbak DF, Nordgard S, Stovner LJ, Linde M, Folvik M, Bugten V, et al. Pilot study of sphenopalatine injection of onabotulinumtoxinA for the treatment of intractable chronic cluster headache. Cephalalgia. 2016;36(6):503-9.

102. Lipton RB, Dodick DW, Ailani J, Lu K, Finnegan M, Szegedi A, et al. Effect of ubrogepant vs placebo on pain and the most bothersome associated symptom in the acute treatment of migraine: the ACHIEVE II randomized clinical trial. JAMA. 2019;322(19):1887-98.

103. Lipton RB, Croop R, Stock EG, Stock DA, Morris BA, Frost $\mathrm{M}$, et al. Rimegepant, an oral calcitonin generelated peptide receptor antagonist, for migraine. $\mathrm{N}$ Engl J Med. 2019;381(2):142-9.

104. Goadsby PJ, Dodick DW, Ailani J, Trugman JM, Finnegan M, Lakkis $\mathrm{H}$, et al. Orally administered atogepant was efficacious, safe, and tolerable for the prevention of migraine: results from a phase $2 b / 3$ study. Headache. 2019;59:18-9.

105. Biohaven achieves positive topline results in pivotal phase 2/3 study of vazegepant, the first and only intranasal CGRP receptor antagonist in clinical development for the acute treatment of migraine. New Haven, CT: Biohaven Pharmaceuticals; Published December 17, 2019. [press release].

106. Rubio-Beltran E, Labastida-Ramirez A, Villalon CM, MaassenVanDenBrink A. Is selective 5-HT1F receptor agonism an entity apart from that of the triptans in antimigraine therapy? Pharmacol Ther. 2018;186:8897.

107. Vila-Pueyo MSL, Page K, Loaraine H, Kovalchin J, Goadsby PJ, et al. Lasmiditan inhibits trigeminovascular nociceptive transmission. Cephalalgia. 2016;36(1S):152 [Abstract].

108. Labastida-Ramirez A, Rubio-Beltran E, Haanes KA, Chan KY, Garrelds IM, Johnson KW, et al. Lasmiditan inhibits calcitonin gene-related peptide release in the rodent trigeminovascular system. Pain.

2020;161(5):1092-9.

109. Goadsby PJ, Wietecha LA, Dennehy EB, Kuca B, Case $\mathrm{MG}$, Aurora SK, et al. Phase 3 randomized, placebocontrolled, double-blind study of lasmiditan for acute treatment of migraine. Brain. 2019;142(7):1894904.

110. Nelson DL, Phebus LA, Johnson KW, Wainscott DB, Cohen ML, Calligaro DO, et al. Preclinical pharmacological profile of the selective 5-HT1F receptor agonist lasmiditan. Cephalalgia. 2010;30(10):1159-69.

111. Snoer A, Vollesen ALH, Beske RP, Guo S, Hoffmann J, Fahrenkrug J, et al. Calcitonin-gene related peptide and disease activity in cluster headache. Cephalalgia. 2019;39(5):575-84.

112. Goadsby PJ. Cluster headache and the trigeminalautonomic reflex: driving or being driven? Cephalalgia. 2018;38(8):1415-7.

113. Goadsby PJ, Uddman R, Edvinsson L. Cerebral vasodilatation in the cat involves nitric oxide from parasympathetic nerves. Brain Res. 1996;707(1):110-8. 
114. Hoffmann J, Goadsby PJ. New agents for acute treatment of migraine: CGRP receptor antagonists, iNOS inhibitors. Curr Treat Options Neurol.

2012;14(1):50-9.

115. D'Amico D, Leone M, Ferraris A, Catania A, Carlin A, Grazzi L, et al. Role of nitric oxide in cluster headache. Ital J Neurol Sci. 1999;20(2 Suppl):S25-7.

116. Hoffmann J, Miller S, Martins-Oliveira M, Akerman S, Supronsinchai W, Sun H, et al. PAC1 receptor blockade reduces central nociceptive activity: new approach for primary headache? Pain. 2020;161(7):1670-81.

\section{Publisher's Note}

Springer Nature remains neutral with regard to jurisdictional claims in published maps and institutional affiliations. 